\title{
Um diálogo entre arquivo, conhecimento e tecnologia
}

\author{
Henrique Machado dos Santos \\ Daniel Flores \\ Universidade Federal de Santa Maria - UFSM, Brasil
}

\section{REVIEW}

\begin{abstract}
Resumo
Objetivo. Realizar uma breve reflexão sobre a gestão do conhecimento em arquivos, enfatizando as ligações necessárias para um diálogo entre arquivo, conhecimento e tecnologia.

Método. Consiste na revisão de materiais previamente publicados das áreas da Administração, Arquivologia e Ciência da Informação. As fontes consultadas consistem em livros, teses, textos em sites da internet e artigos científicos de periódicos indexados no Google Scholar. Assim, os dados coletados são analisados de forma qualitativa.

Resultados. Há uma estreita relação entre o arquivo, o conhecimento e a tecnologia. Neste sentido, o documento exerce o papel de interlocutor deste diálogo. O cenário interdisciplinar vislumbrado, realça a aproximação existente entre as práticas arquivísticas e a gestão do conhecimento, de modo que possibilite um ciclo de retroalimentação que servirá de apoio às práticas relacionadas à gestão, seja ela, do conhecimento, da informação ou de documentos.

Conclusões. Há necessidade de mais estudos que abordem o potencial dos arquivos, a fim de preencher possíveis lacunas teóricas, assim, múltiplos olhares alcançarão mais pontos de convergência interdisciplinares. Por fim, destaca-se que o potencial informacional dos arquivos, então mediado pelas tecnologias da informação, poderá enriquecer as práticas de gestão do conhecimento, e para isto, é essencial reforçar as relações interdisciplinares entre Administração, Arquivologia e Ciência da Informação.
\end{abstract}

Palavras-chave

Tecnologia da informação; Arquivos; Arquivologia; Gestão do conhecimento; Documentos arquivísticos digitais; Interdisciplinaridade

\section{A dialogue between archive, knowledge and technology}

\section{Abstract}

Objective. Perform a brief reflection on knowledge management in archives, emphasizing the connections necessary for a dialogue between archive, knowledge and technology.

Method. It consists in review of material previously published in the areas of Management Science, Archival Science and Information Science. The sources consulted consist of books, theses, texts on websites and scientific journal articles indexed in Google Scholar. Thus, the collected data is analyzed qualitatively.

Results. There is a close relationship between the archive, knowledge and technology. In this sense, the document has the role of interlocutor in this dialogue. The interdisciplinary scenario envisioned, enhance existing rapprochement between the archival practices and knowledge management, in order to make possible a feedback cycle that will support the practices related to the management, either, of knowledge, of information or of documents.

Conclusions. There is need for further studies to address the potential of the archives in order to fill possible gaps theory thus reach multiple looks more points interdisciplinary convergence. Finally, there is the informational potential of archives, then mediated by technology information, can enrich the knowledge management practices, and for this it is essential to strengthen the interdisciplinary relationships between Management Science, Archival Science and Information Science.

Keywords

Information technology; Archives; Archival Science; Knowledge management; Digital archival documents; Interdisciplinarity 


\section{Introdução}

O poder de inovação das tecnologias da informação conquistou espaço na sociedade contemporânea, bem como nas práticas arquivísticas (LOPES, 1997). Observa-se que a Arquivologia vem agregando novas relações interdisciplinares, e assim, vislumbrando novos caminhos.

Após a ruptura com o passado marcado pela submissão, onde as práticas do profissional se restringiam aos arquivos históricos, a Arquivologia passa por um período de reformulação de suas bases epistemológicas. Assim, o profissional modifica a sua visão, e começa perceber que os arquivos são fontes de informação e conhecimento, além disto, as tecnologias da informação se tornaram indispensáveis para uma gestão eficiente.

Como resultado de uma evolução natural, a Arquivologia deixa de desempenhar o papel de ciência auxiliar da História, tornando-se uma ciência autônoma. As relações interdisciplinares com a História continuam existindo, e a novidade passa a ser o surgimento de novas relações interdisciplinares, principalmente como a Administração e com a Ciência da Informação.

Pode-se atribuir a aproximação entre a Arquivologia e a Administração às práticas de gestão documental, isto porque através da gestão se estabeleceram métodos e rotinas, com o objetivo de racionalizar, seja na produção, manutenção, uso ou avaliação dos documentos arquivísticos (MORENO, 2008). Desta forma, descobre-se que as práticas de gestão documental, auxiliam as rotinas administrativas, além da possibilidade de contribuir com a gestão do conhecimento organizacional. Identifica-se assim, que os arquivos correntes, intermediários e permanentes são fontes de informações, e que se forem organizadas poderão gerar conhecimentos fundamentais para o contexto organizacional.

Tendo em vista o contexto apresentado, este artigo tem por objetivo realizar uma reflexão sobre como as práticas arquivísticas poderão auxiliar no processo de gestão do conhecimento organizacional. Neste sentido, enfatizam-se três aspectos centrais que são: a evolução das tecnologias de informação; o potencial dos documentos arquivísticos; e a gestão do conhecimento organizacional.

O método utilizado para esta reflexão consiste em realizar um levantamento bibliográfico de materiais previamente publicados que abordem as práticas arquivísticas, a gestão do conhecimento e o advento das tecnologias da informação. Os dados coletados são analisados de forma qualitativa constituindo uma breve revisão de literatura que é concatenada em seções temáticas (LUNA, 1997; SILVA; MENEZES, 2005).

\section{A influência das tecnologias da informação}

Os constantes e acelerados avanços das tecnologias, bem como a complexidade dos sistemas tiveram um forte impacto na sociedade, ocasionando assim, o aumento das necessidades de ordem administrativa, jurídica e científica. Da mesma forma, a produção e o volume de documentos, então impulsionados pelos sistemas burocráticos, cresceram em um ritmo assustador (BELLOTTO, 2006). Neste sentido, a arquivologia vivencia um momento de pró-atividade no qual as atividades de gestão documental adquirem um papel fundamental na administração organizacional.

A gestão documental tem por objetivo preservar e dar acesso aos documentos de maneira ágil e eficaz. De certa forma, busca reduzir a massa documental produzida de forma a otimizar os recursos utilizados (MORENO, 2008). Vale lembrar que o documento vem se tornando fundamental no âmbito organizacional, o que pode ser justificado pela moderna burocracia, na qual diversos procedimentos são mediados por documentos. Desta forma, é preciso ter um controle da massa documental a fim de agilizar o fluxo de processos.

Além do aumento da produção de documentos, ocorreu a demanda por tecnologias da informação, que por vezes auxiliam nas atividades de produção documental. Além disso, há diversas ferramentas que podem gerenciar as atividades organizacionais, seja monitorando processos, ou delegando tarefas. Destaca-se que a tecnologia está exercendo um papel fundamental nas práticas de administração em virtude de sua demanda então motivada por mais eficiência e maior competitividade. Neste sentido, as fontes de conhecimento se configuram como um diferencial da moderna administração, e o aproveitamento deste potencial depende do seu tratamento desde a produção, perpassando o seu armazenamento, até o seu reuso.

As organizações de modo geral, precisam considerar a gestão de dados/informações/documentos como uma etapa importante para o seu sucesso. Estes materiais podem ajudar a tomar as decisões corretas, podendo desenvolver uma vantagem competitiva e maior rentabilidade (SOUSA, 2015). 
Da mesma forma que as tecnologias auxiliam, elas também vêm causando a dependência das organizações, a qual não se limita somente ao uso de computadores. A necessidade de artefatos tecnológicos extrapolou os limites das máquinas, chegando aos softwares, prova disso são os sistemas informatizados, considerados vitais para o correto funcionamento organizacional.

Vive-se uma era onde a tecnologia está presente na vida das pessoas. Além disso, os avanços informáticos, com ênfase nos computadores, vêm exercendo forte influência sobre as organizações de modo geral. É muito difícil encontrar organizações ou processos que não foram transformados pelas novas tecnologias (ROSINI; PALMISANO, 2003). Os tradicionais mecanismos de controle e registro foram profundamente alterados, e assim remodelados conforme as funcionalidades disponibilizadas pelas tecnologias da informação. Posteriormente, as tecnologias seguiram evoluindo assim como as suas funcionalidades implícitas, assim, as expectativas para 0 futuro são ferramentas mais completas e, principalmente, mais complexas, o que vem a afetar diretamente os profissionais que trabalham com gestão, preservação e acesso à informação.

A rápida evolução dos sistemas computacionais e da tecnologia da informação tornou possível a capacidade dos sistemas de informação integrar uma organização complexa (SCHUSTER; SILVA FILHO, 2005). Logicamente que a implementação de sistemas deverá ser precedida de um conjunto de análises criteriosas. Inicialmente, é preciso definir quais são os requisitos, e posteriormente, procede-se a avaliação para então verificar a conformidade do sistema. No caso da gestão do conhecimento, o sistema deverá se adaptar as diferentes formas de coleta de conhecimento, buscando assim, maior eficiência e aproveitamento dos recursos organizacionais.

No âmbito da Arquivologia pode-se destacar que "o avanço tecnológico mudou radicalmente os mecanismos de registro e de comunicação da informação nas instituições e, consequentemente, seus arquivos também mudaram" (RONDINELLI, 2005, p. 24). Desta forma, os "arquivos contemporâneos" foram invadidos por inovações, dentre elas: ferramentas de Gestão Eletrônica de Documentos (GED) e documentos digitais. Neste contexto, há ainda a preocupação com a preservação dos documentos digitais:

Nesse avanço vertiginoso da tecnologia, propiciado pelo crescente conhecimento científico, as sociedades contemporâneas esperam contar com o domínio de recursos digitais para garantir o acesso de longo prazo a grandes estoques informacionais. A nossa dependência da tecnologia moderna nos conduz ao risco da perda dos registros materiais da investigação racional (MÁRDERO ARELLANO, 2008, p. 32).

Parte dos riscos com relação à perda se justifica pelo fato da tecnologia ter evoluído tão rapidamente, de modo que o conhecimento sobre gestão e preservação não acompanhou o seu ritmo. Diversos fatores como, por exemplo, a mudança de suporte, a necessidade de um aparato tecnológico específico, a variedade de hardware e software, contribuíram para uma evolução voraz e desenfreada.

Durante séculos, o papel foi o principal suporte para registro e armazenamento da informação e do conhecimento. Em virtude dos avanços tecnológicos, o suporte adotado passou a ser o digital, o qual favoreceu o crescimento da produção de conteúdo técnico e científico em todo o mundo. Outra vantagem da informação em meio digital é a rapidez de sua disseminação (SOUZA; OLIVEIRA; D’AVILA; CHAVES, 2012, p. 66).

A sociedade vive uma fase de transição dos documentos em suporte papel para os documentos em suporte digital (MARCONDES, 2010). Agora impulsionados pela praticidade de criação, tramitação e difusão, os documentos digitais se expandiram na sociedade contemporânea, atingindo altos patamares com relação a sua relevância social, informacional e cultural. Neste contexto, as práticas de GED, preservação digital, curadoria digital, acesso aberto, bibliotecas digitais, repositórios digitais, e outros, são assuntos cada vez mais difundidos pela Ciência da Informação e suas relações interdisciplinares, por exemplo, Arquivologia, Biblioteconomia e Informática. Observa-se que estas discussões poderão ser enriquecidas com as práticas de gestão do conhecimento, possibilitando a organização e o tratamento de sua informação, estabelecendo assim, um ciclo de retroalimentação.

\section{A gestão do conhecimento}

Pode-se definir a gestão do conhecimento como "o conjunto de processos, práticas e procedimentos que visam identificar, registrar e gerenciar o conhecimento das pessoas de forma a garantir sua utilização, difusão e aplicação no âmbito institucional" (SANTOS, 2007, p. 191). Conforme Silva Filho e Silva (2005) existem 
diferentes tipos de conhecimento que podem ser classificados em: conhecimento explícito e conhecimento tácito. O conhecimento explícito pode ser definido como:

[...] um conhecimento útil, tal como um dado ou uma informação. Esse tipo de conhecimento está registrado e pode ser facilmente processado, armazenado e transmitido. O conhecimento explícito pode ser transmitido, por exemplo, por meio de aulas, livros ou manuais de instruções (SILVA FILHO; SILVA, p. 28, 2005).

Já "o conhecimento tácito possui uma qualidade pessoal" (SILVA FILHO; SILVA, p. 28, 2005). É o conhecimento que está restrito ao indivíduo e que ainda não foi registrado. Rosini e Palmisano (2003) explicam sobre o processo de transformação do conhecimento tácito em explícito:

Dar visibilidade ao conhecimento na organização, transformar o conhecimento tácito em explícito é um dos grandes desafios fundamentais da gestão do conhecimento, em que é importante haver maturidade entre a distinção e percepção e a transferência de conhecimento (ROSINI; PALMISANO, p. 139-140, 2003).

O conhecimento precisa ser compartilhado com qualidade, além de estar disponível para as pessoas interessadas às quais tem o direito de acesso, lógico que para isto é preciso implementar ferramentas de tecnologia que definam as propriedades de acesso. Uma boa gestão do conhecimento implica em boa produção, seleção, transformação, distribuição, avaliação e preservação do conhecimento, deve-se lembrar de que ele constitui um ativo organizacional de valor primordial.

Uma vez gerado o conhecimento, ele pode permanecer em seu estado original, de forma abstrata e tácita, residente exclusivamente na mente do detentor ou ser devidamente documentado, explicitado e, portanto, passível de ser compartilhado entre os demais membros da organização. Assim, o conhecimento organizacional, aquele que pode ser considerado um ativo da organização, ou seja, mais facilmente agregar valor a organização, é o já explicitado (conhecimento explícito) (DE SORDI, 2008, p. 12).

Parte considerável do conhecimento explícito está registrada sob a forma de documentos arquivísticos, os quais são originados naturalmente no decorrer das atividades da organização. Sem uma gestão de documentos eficaz, as atividades de gestão do conhecimento tornam-se mais dispendiosas, pois a recuperação da informação torna-se mais lenta, e por vezes os documentos contendo conhecimentos significativos não são localizados. Tais dificuldades podem ser ocasionadas pela ausência de sistemas informatizados de gestão, preservação e acesso, como também pela perda ou eliminação indevida dos documentos.

\section{0 arquivo como fonte de conhecimento}

A gestão de documentos, quando implementada por profissionais da Arquivologia em conjunto com a equipe interdisciplinar fornece a gestão do conhecimento, ferramentas fundamentais para a gestão do conhecimento explícito (INNARELLI, 2012). Pode-se afirmar que "apenas exercendo corretamente suas funções tradicionais, o arquivista já contribui positivamente com a gestão de conhecimento" (SANTOS, 2007, p. 203). As funções arquivísticas: produção, aquisição, classificação, avaliação, conservação, descrição e difusão (ROUSSEAU; COUTURE, 1998), representam o papel desempenhado pelo arquivista no ciclo documental. Da mesma forma que estas sete funções tratam dos documentos, também estão tratando do conhecimento contido nos mesmos, fato que reforça a afirmação de (SANTOS, 2007) mencionada anteriormente.

Considerando o contexto atual, onde as tecnologias da informação estão cada vez mais disseminadas na sociedade, e da mesma forma ocorre à demanda por documentos digitais, torna-se fundamental a boa gestão informatizada. Desta forma, o conhecimento registrado em documentos digitais estará sujeito às vantagens e desvantagens impostas pela tecnologia.

\footnotetext{
O conhecimento quando preservado a partir dos documentos arquivísticos digitais e seus processos informatizados permitirá seu compartilhamento no futuro. Compartilhamento que garantirá a perpetuação de conhecimento explícito seja qual for à tecnologia utilizada pelas próximas gerações (INNARELLI, 2012, p. 62).
}

Deve-se ressaltar que a preservação de documentos digitais ainda é um dos grandes desafios das comunidades da Arquivologia, Informática, Ciência da informação e áreas afins. Sendo assim, destaca-se a importância dos estudos de preservação digital no âmbito da gestão do conhecimento intermediada pela tecnologia da informação e por documentos digitais. 
A rápida obsolescência das tecnologias causa incertezas quanto ao contexto tecnológico de hardware, software e suporte, e quanto aos conhecimentos sobre estes. Na medida em que não houver conhecimentos suficientes sobre o material a ser preservado, não haverá garantias de recuperação em longo prazo. Neste sentido, identifica-se a necessidade de práticas como a gestão do conhecimento, de modo que venha a apoiar as atividades de preservação digital (SANTOS; FLORES, 2015, p. 49).

De certa forma, pode-se considerar que a preservação digital depende de uma boa prática de gestão do conhecimento. Além disso, ambas podem atual num cenário de retroalimentação, onde se preservam conhecimentos por intermédio de documentos digitais.

Preservar os documentos arquivísticos é preservar o conhecimento registrado, embora muitas vezes este conhecimento não esteja sendo aproveitado devido às ausências de práticas de gestão do conhecimento ou mesmo ao desconhecimento do potencial dos arquivos. É possível alimentar bases de conhecimento por intermédio das informações contidas nos documentos, para isto é preciso ter boa gestão organizacional e tecnológica, além da preservação documental.

Os documentos podem prover informações sobre clientes, produtos e fornecedores, proporcionando assim, a realização de análises qualitativas e quantitativas, e tendo como resultado uma base de conhecimentos planificados. Estatísticas de lucros e de prejuízos podem indicar possíveis caminhos que devem ou não ser seguidos, ou seja, tanto o conhecimento do que deu certou, quanto do que não deu certo, deve ser planificado a fim de contribuir para o aprendizado da organização.

\section{Convergência e Interdisciplinaridade}

As organizações contemporâneas estão investindo cada vez mais na gestão do conhecimento e consequentemente, nas tecnologias da informação e comunicação, ambas são fatores de competitividade, que visam a melhoria dos processos e de inovação. Entretanto, por vezes está-se atropelando e negligenciando conceitos da gestão do conhecimento e de áreas afins, como a Ciência da Informação e a Arquivologia (INNARELLI, 2012). Além da exclusão proporcionada pela competitividade, por vezes ocorre uma submissão, ou falta de percepção das contribuições que as atividades profissionais desempenhadas têm a contribuir com a gestão do conhecimento. Neste sentido, o arquivista deve considerar que sua função não se limita a apenas preservar a documentação, mas também promover o acesso, intervir na administração organizacional, mostrando as contribuições de suas atividades profissionais.
A função do arquivista é revelar os tesouros de pesquisa a ele confiados e não monopolizá-los e impedir sua consulta. Uma atitude de domínio e reserva em relação ao acervo é imperdoável ao arquivista. Deve registrar seu conhecimento no papel e não o guardar apenas na cabeça. Deve descrever o material sob sua guarda de maneira que outros, usando as descrições por ele feitas, possam se inteirar do conteúdo, arranjo e valor daquele. E, à medida que prossegue no seu trabalho de descrição, o acervo de seu depósito torna-se, gradativamente, mais acessível a todos que com ele trabalham ou que devam consultá-lo (SCHELLENBERG, 2006, p. 313).

Muitas das informações estratégicas que os administradores buscam, podem ser encontradas nos arquivos, e não o são, por uma simples falta de conhecimento e diálogo interdisciplinar. As informações contidas nos documentos convergem para os interesses organizacionais, o grande volume de dados, informações, documentos e conhecimentos, exige uma gestão arquivística de qualidade, apoiada por ferramentas de tecnologia da informação a fim de apoiar a administração.

O plano empresarial exige soluções simples e que permitam reduzir custos para obter melhores resultados. Desta forma, a gestão documental torna-se a base para as empresas construírem o seu sucesso (SOUSA, 2015). Deve-se destacar que as vantagens do plano empresarial são facilmente transcritas para um plano, o organizacional, contemplando os setores público e privado.

De Sordi (2008), embora não mencione a Arquivologia de forma direta em sua obra, faz apontamentos para dados, informações e conhecimentos, que poderão ser facilmente obtidos através dos documentos arquivísticos:

Com a contínua expansão dos dados que circulam pelas organizações, abrangendo dados cadastrais de clientes, parceiros, fornecedores, funcionários, materiais, ativos e, principalmente, das transações destes com a organização (compra, devolução, uso, manutenção, pagamento, opinião, avaliação, descarte, etc.), pode-se obter informações e 
conhecimentos úteis, seja para melhoria dos atuais produtos e serviços, permitindo, inclusive, o ingresso da organização em novos seguimentos do sócio, de forma distinta daqueles já estabelecidos no seguimento. Evidentemente, quanto maior o desafio almejado, maior deverá ser o preparo da organização no que tange aos recursos: dados, informações e conhecimento. Nesse sentido, a discussão da participação destes perante a estratégia da empresa é fundamental (DE SORDI, 2008, p. 3).

Neste contexto, a evolução da tecnologia da informação vem reformulando as organizações (SCHUSTER; SILVA FILHO, 2005), e para sobreviver é preciso inovar (SCHUSTER; SILVA FILHO; CALIL, 2005). Novas tecnologias como, por exemplo, os repositórios de dados, vêm sendo fundamentais para a tomada de decisão. Entretanto deve-se realizar um tratamento preliminar profundo que reduza as informações recuperadas e aumentando a qualidade das respostas (SANTOS, 2007). Não basta informatizar a administração e o arquivo, sem realizar um planejamento sobre bases sólidas, vale lembrar que "a informação desorganizada, quando informatizada, continua sendo apenas informação desorganizada” (LOPEZ, 2002, p. 48). Em outras palavras, para a gestão do conhecimento, é preciso garantir a qualidade da informação que circula em meio digital, o que pode ser alcançado através de uma gestão de documentos eficaz.

\section{Conclusões}

Este artigo realizou uma reflexão interdisciplinar, correlacionando a influência da evolução das tecnologias da informação e as contribuições da Arquivologia para as práticas de gestão do conhecimento. Neste contexto, os documentos de arquivo podem contribuir para a gestão do conhecimento por intermédio das tecnologias da informação, as quais têm por finalidade agilizar o processo de recuperação da informação registrada.

Inicialmente discorreu-se sobre a evolução das tecnologias da informação e a sua influência na sociedade contemporânea, e posteriormente, identificas as suas convergências com a Arquivologia. Neste sentido, buscouse transcrever a nova imagem desta ciência, agora dotada de autonomia e, buscando novas relações interdisciplinares. O argumento utilizado para as relações com a administração organizacional foi a gestão de documentos, sendo considerada uma atividade de apoio a administração. Desta forma, foi chamada a atenção para o potencial do arquivo, que muitas vezes não é utilizado por parte dos gestores nas tomadas de decisão. Além disso, a área de arquivo apresenta algumas tendências, dentre elas, a demanda por documentos digitais, 0 que se reflete na sociedade como um todo, fato que reforça a necessidade de práticas de gestão e preservação de documentos.

Após a conceituação de gestão do conhecimento, partiu-se para o aprofundamento da questão do arquivo, identificando o papel do profissional arquivista na gestão do conhecimento. Identificou-se que o arquivo é uma fonte de conhecimentos organizacionais, podendo ser considerado um ativo da organização. Desta forma, a presença de ferramentas de tecnologia da informação auxiliará os processos de gestão de documentos digitais e tradicionais, e desta forma, contribuirá para a gestão do conhecimento em arquivos.

Considerando a importância de integrar a tecnologia da informação e os arquivos na gestão do conhecimento, torna-se imprescindível defender uma abordagem interdisciplinar, agregando referenciais e práticas de diversas áreas. Neste sentido é reforçada a necessidade de mais diálogos horizontais, identificando as diversas contribuições no âmbito da gestão do conhecimento. Observa-se um importante ciclo de retroalimentação: a tecnologia da informação apoia a gestão, seja ela, organizacional, de documentos ou do conhecimento, e estas, se apoiam mutuamente.

Por fim, este estudo apresentou uma breve reflexão da gestão do conhecimento no âmbito dos arquivos. Embora sua base teórica esteja mais próxima da Arquivologia, é de fácil compreensão interdisciplinar. Desta forma, poderá contribuir para diálogos mais amplos sobre gestão do conhecimento, destacando o papel catalizador do arquivo como uma fonte em potencial de conhecimentos organizacionais. Dentre as limitações presentes neste trabalho, pode-se destacar que a gestão do conhecimento em arquivos é abordada sob a ótica da Arquivologia. Desta forma, recomendam-se estudos futuros que analisem e discutam sob a ótica da Administração, Ciência da Informação, e áreas afins. 


\section{Referências}

BELLOTTO, Heloísa Liberalli. Arquivos permanentes: tratamento documental. 4. Ed. Rio de Janeiro: FGV, 2006,320 p.

DE SORDI, José Osvaldo. Administração da informação: fundamentos e práticas para uma nova gestão do conhecimento. São Paulo: Saraiva, 2008, 185p.

INNARELLI, Humberto Celeste. Preservação digital: a gestão e a preservação do conhecimento explícito digital em instituições arquivísticas. InCID: Revista de Ciência da Informação e Documentação, Ribeirão Preto, v. 3, n. 2, p. 48-63, jul./dez. 2012 Disponível em: <http://www.revistas.usp.br/incid/article/view/48653>. Acesso em: 28 dez. 2014.

LOPES, Luís Carlos. A gestão da informação: as organizações, os arquivos e a informação aplicada. Rio de Janeiro: Arquivo Público do Estado do Rio de Janeiro. 1997, 143p.

LOPEZ, André Porto Ancona. Como descrever documentos de arquivo: elaboração de instrumentos de pesquisa. São Paulo: Arquivo do Estado, 2002, 57 p. (Projeto como fazer; v. 6).

LUNA, Sergio Vasconcelos de. Planejamento de pesquisa: uma introdução. São Paulo: EDUC, 1997.

MARCONDES, Carlos Henrique. Linguagem e documento: fundamentos evolutivos e culturais da Ciência da Informação Perspectivas em Ciência da Informação, v. 15, n. 2, p 2-21, maio./ago. 2010. Disponível em: <http://portaldeperiodicos.eci.ufmg.br/index.php/pci/article/view/1019>. Acesso em: 10 fev. 2015

MÁRDERO ARELLANO, Miguel Ángel. Critérios para a preservação digital da informação científica. 354 p. Tese (Doutorado em Ciência da Informação). Universidade Federal de Brasília, Departamento de Ciência da Informação, 2008. Disponível em: <http://bdtd.bce.unb.br/tedesimplificado/tde busca/arquivo.php?codArquivo=4547>. Acesso em: 15 jun. 2014

MORENO, Nádina Aparecida. Gestão documental ou gestão de documentos: trajetória histórica. In: Gestão em arquivologia abordagens múltiplas. Linete Bartalo e Nádina Aparecida Moreno (Orgs.). Londrina: EDUEL, 2008, 188 p. p. 71-88.

RONDINELLI, Rosely Curi. Gerenciamento arquivístico de documentos eletrônicos: uma abordagem teórica da diplomática arquivística contemporânea. 4. Ed. Rio de Janeiro: FGV, 2005, 160 p.

ROSINI, Alessandro Marco; PALMISANO, Angelo. Administração de Sistemas de Informação e a Gestão do Conhecimento. São Paulo: Pioneira Thomson Learning, 2003.

ROUSSEAU, Jean-Yves; COUTURE, Carol. Os fundamentos da disciplina arquivística. Lisboa: Publicações Dom Quixote, 1998. Tradução: Magda Bigotte Figueiredo (Trabalho original publicado em 1994).

SANTOS, Henrique Machado dos; FLORES, Daniel. As vulnerabilidades dos documentos digitais: Obsolescência tecnológica e ausência de políticas e práticas de preservação digital. Biblios: Revista de Bibliotecología y Ciencias de la Información, Lima, n. 59, p. 45-54, 2015. Disponível em: <http://biblios.pitt.edu/ojs/index.php/biblios/article/view/215>. Acesso em: 04 jul. 2015.

SANTOS, Vanderlei Batista dos. A prática arquivística em tempos de gestão do conhecimento. In: SANTOS, Vanderlei Batista dos. Arquivística: temas contemporâneos. Distrito Federal: SENAC, 2007, p. 175-223.

SCHELLENBERG, Theodore Roosevelt. Arquivos modernos: princípios e técnicas. 6. ed. Rio de Janeiro: FGV, 2006. 386 p. Tradução: Nilza Teixeira Soares. (Trabalho original publicado em 1956).

SCHUSTER, Carlos Eduardo; SILVA FILHO, Cândido Ferreira da. Sistemas de Informação para a Gestão do Conhecimento. In: Tecnologia da informação para a gestão do conhecimento: teoria e estudos em organizações. Cândido Ferreira da Silva Filho e Lucas Frazão Silva (Orgs.). Campinas, SP: Alínea, 2005.

SCHUSTER, Carlos Eduardo; SILVA FILHO, Cândido Ferreira da; CALIL, José Francisco. Tecnologia da Informação para a Gestão do Conhecimento: Um estudo em uma empresa do setor de bebidas. In: Tecnologia da informação para a gestão do conhecimento: teoria e estudos em organizações. Cândido Ferreira da Silva Filho e Lucas Frazão Silva (Orgs.). Campinas, SP Alínea, 2005

SILVA FILHO, Cândido Ferreira da; SILVA, Lucas Frazão. Da Aprendizagem à Gestão do Conhecimento. In: Tecnologia da informação para a gestão do conhecimento: teoria e estudos em organizações. Cândido Ferreira da Silva Filho e Lucas Frazão Silva (Orgs.). Campinas, SP: Alínea, 2005.

SILVA, Edna Lúcia da; MENEZES, Estera Muszkat. Metodologia da pesquisa e elaboração de dissertação. 4. Ed. rev atual. Florianópolis, UFSC, 2005. Disponível em:

$<$ https://projetos.inf.ufsc.br/arquivos/Metodologia de pesquisa e elaboracao de teses e dissertacoes 4ed.pdf $>$. Acesso em: 13 jun. 2014

SOUSA, Carlos. Gestão Documental: a base que alicerça o sucesso empresarial. Sapotek. Disponível em: <http://tek.sapo.pt/opiniao/opiniao gestao documental a base que alicerca 1434448.html>. Acesso em: 17 mar. 2015. 
SOUZA, Arthur Heleno Lima Rodrigues de; OLIVEIRA, Alexandre Faria de; D’AVILA, Raquel Tavares; CHAVES, Erinalva da Silva Sales. O modelo de referência OAIS e a preservação digital distribuída. Ciência da Informação, Brasília, v. 41, n. 1, p. 65-73, jan./abr., 2012. Disponível em: <http://revista.ibict.br/index.php/ciinf/article/view/2118>. Acesso em: 18 mar. 2015.

\section{Dados dos autores}

Henrique Machado dos Santos

Bacharel em Arquivologia pela Universidade Federal de Santa Maria (UFSM). Arquivista do escritório Martini, Medeiros \& Tonetto: advogados associados. Integrante dos grupos de pesquisa CNPq-UFSM: Gestão Eletrônica de Documentos Arquivísticos (GED/A) e Patrimônio Documental Arquivístico (PDA). Brasil.

henrique.gralha@gmail.com

\section{Daniel Flores}

Doutor em Metodologías y Líneas de Investigación en Biblioteconomía y Documentación pela Universidad de Salamanca (USal). Professor Adjunto do Departamento de Documentação e do Mestrado em Patrimônio Cultural da Universidade Federal de Santa Maria (UFSM). Líder dos grupos de pesquisa CNPq-UFSM: Gestão Eletrônica de Documentos Arquivísticos (GED/A) e Patrimônio Documental Arquivístico (PDA). Brasil.

dfloresbr@gmail.com

Recebido - Received : 2015-07-28

Aceitado - Accepted : 2015-09-26

\section{(cc) EY}

This work is licensed under a Creative Commons Attribution 4.0

United States License.

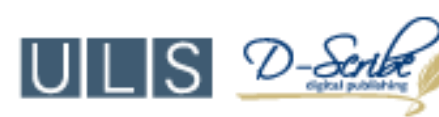

This journal is published by the University Library System of the University of Pittsburgh as part of its D-Scribe Digital Publishing Program and is cosponsored by the University of Pittsburgh Press. 